\title{
Vitamin C Measurement
}

National Cancer Institute

\section{Source}

National Cancer Institute. Vitamin C Measurement. NCI Thesaurus. Code C74903.

The determination of the amount of Vitamin C present in a sample. 